\title{
Disseminated carcinomatosis of the bone marrow with disseminated intravascular coagulation as the first symptom of recurrent rectal cancer successfully treated with chemotherapy: A case report and review of the literature
}

\author{
HIROSHI TAKEYAMA $^{1}$, TSUTOMU SAKIYAMA ${ }^{2}$, TOMOKO WAKASA ${ }^{3}$, \\ KOTARO KITANI ${ }^{1}$, KEISUKE INOUE ${ }^{1}$, HIROAKI KATO ${ }^{1}$, SHINYA UEDA ${ }^{2}$, MASANORI TSUJIE ${ }^{1}$, \\ YOSHINORI FUJIWARA ${ }^{1}$, MASAO YUKAWA ${ }^{1}$, YOSHIO OHTA ${ }^{3}$ and MASATOSHI INOUE ${ }^{1}$ \\ Departments of ${ }^{1}$ Gastroenterological Surgery, ${ }^{2}$ Medical Oncology and ${ }^{3}$ Pathology, \\ Nara Hospital, Faculty of Medicine, Kinki University, Nara 630-0293, Japan
}

Received January 4, 2016; Accepted October 28, 2016

DOI: $10.3892 / 01.2017 .5983$

\begin{abstract}
Disseminated carcinomatosis of the bone marrow (DCBM) is a condition in which bone marrow (BM) metastases diffusely invade the BM, and is frequently accompanied by disseminated intravascular coagulation (DIC). While prostate, lung, breast and stomach malignancies, in addition to neuroblastoma, are the most prevalent non-hematological malignancies to metastasize frequently to the $\mathrm{BM}$, colorectal cancer is a malignancy that rarely metastasizes to the BM. The present case describes a 65 -year-old male patient treated by resection and one course adjuvant chemotherapy for stage IIIC rectal cancer who presented with nasal bleeding at 8 months post-surgery. A blood test exhibited DIC. A BM biopsy was performed and the definitive diagnosis was DCBM with DIC. Promptly, anti-DIC treatment and chemotherapy with a modified FOLFOX6 (folinic acid, leucovorin (LV), 5-fluorouracil (5-FU) and oxaplatin) regimen was started. Following 1 cycle of chemotherapy, DIC was improved and subsequent to 2 cycles of modified FOLFOX6 the patient was discharged. The patient was alive 263 days subsequent to the diagnosis of DIC, but succumbed to carcinomatous meningitis as a result of disease progression. To the best of our knowledge, this is the first report of DCBM with DIC of curatively resected rectal cancer as the first presentation of relapse that was successfully treated with aggressive therapy, including chemotherapy.
\end{abstract}

Correspondence to: Dr Hiroshi Takeyama, Department of Gastroenterological Surgery, Nara Hospital, Faculty of Medicine, Kinki University, Otoda-cho 1248-1, Ikoma, Nara 630-0293, Japan E-mail: htakeyama@nara.med.kindai.ac.jp

Key words: disseminated carcinomatosis of bone marrow, disseminated intravascular coagulation, colorectal cancer, rectal cancer

\section{Introduction}

Disseminated carcinomatosis of the bone marrow (DCBM) is a condition in which diffusely invading bone marrow (BM) metastases are frequently accompanied by disseminated intravascular coagulation (DIC) (1). DCBM of solid tumors is typically recognized as incurable and fatal. Although almost all types of malignancies may metastasize to the BM, the most common non-hematological malignancies are prostate, lung, breast and stomach, in addition to neuroblastoma $(2,3)$.

DCBM of colorectal cancer is relatively rare. DCBM of colorectal cancer has been observed with a frequency of $0-2 \%$ among solid tumors $(2,3)$. DCBM is not necessarily accompanied by DIC (1). Therefore, DCBM with DIC of colorectal cancer is rare in solid tumors. Only 7 cases of DCBM with DIC of colorectal cancer have been reported previously in the literature (Table I) (4-10).

To the best of our knowledge, there has been only one report of DCBM with DIC of curatively resected colon cancer as the first presentation of relapse, but none involving rectal cancer (10). In addition, DCBM with DIC has cancer emergency status, and a definitive diagnosis is sometimes difficult to achieve whilst the patient is alive and able to withstand chemotherapy. In the previous case of DCBM with DIC of colon cancer, the diagnosis was made at postmortem (10). The present study describes a case of DCBM with DIC of rectal cancer as the first presentation of recurrence, which was successfully treated with chemotherapy and resulted in a promising prognosis.

\section{Case report}

The patient was a 65 -year-old male, who presented with anal bleeding and was admitted to Nara Hospital, Faculty of Medicine, Kinki University (Nara, Japan) in June 2014. Written informed consent was obtained from the patient, and the study was ethically approved by the Institutional Research Board of Kinki University Nara Hospital (Nara, Japan). Colonoscopy 


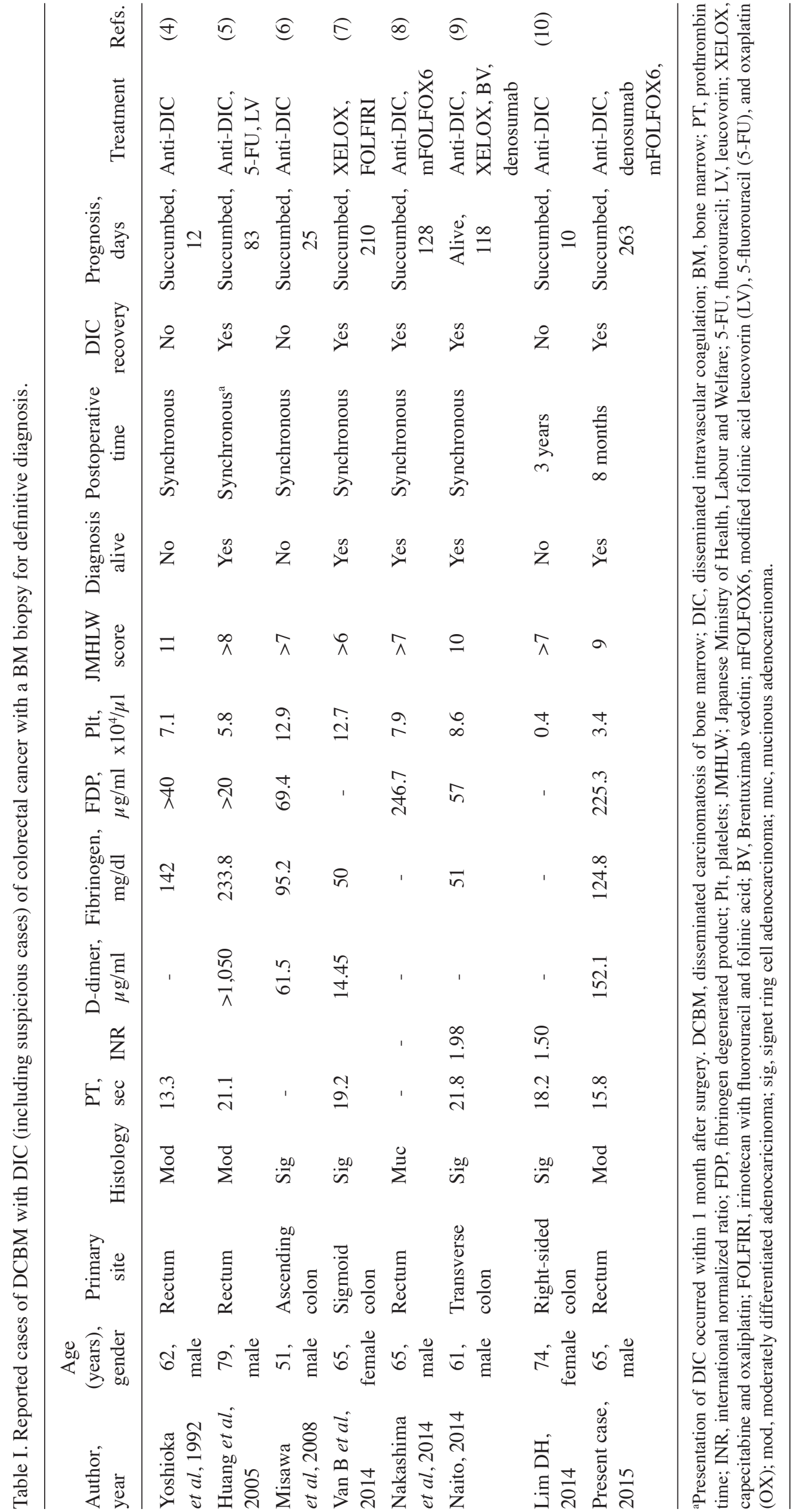


demonstrated the presence of a type 2 rectal tumor. Subsequent histopathological examination of the biopsy from the lesion revealed the presence of adenocarcinoma and the patient was finally diagnosed with rectal cancer. A laparoscopic low anterior resection with ileostomy was performed in July 2014 to prevent anastomotic leakage. The histopathological stage was determined as pT3N2M0, stage IIIC. Two months subsequent to the initial surgery, the patient underwent additional surgery to close the ileostomy. Postoperatively, the patient received adjuvant chemotherapy with $120 \mathrm{mg}$ of oral S-1 for consecutive 28 days followed by a 14-day rest period as 1 course. However, owing to a grade 3 adverse event (vomiting) during the second course, chemotherapy was discontinued. The patient was then followed up regularly with no evidence of disease recurrence.

In February 2015, 8 months subsequent to the first surgery, the patient experienced nasal bleeding and once more consulted Nara Hospital. The patient was diagnosed with DIC based on the DIC score calculated according to DIC diagnostic criteria issued by Japan's Ministry of Health, Labour and Welfare (11). On the first day of admission, initial laboratory data indicated severe thrombocytopenia with a platelet count of $3.4 \times 10^{4} / \mu 1$ (normal range, $13-33 \times 10^{4} / \mu 1$ ), decreased from a count of $33.4 \times 10^{4} / \mu 1$ measured 2 months previously. Initial laboratory data exhibited a white blood cell count of $1.4 \times 10^{4} / \mu 1$ (normal range, $0.4-1.0 \times 10^{4} / \mu 1$ ) and a hemoglobin level of $12.9 \mathrm{~g} / \mathrm{dl}$ (normal range, 12-16 g/dl). The prothrombin time international normalized ratio (PT-INR) was 1.39 (normal range, 0.9-1.13 international normalized ratio), the partial thromboplastin time was $34.0 \mathrm{sec}$ (normal range, $28-40 \mathrm{sec}$ ), the fibrinogen level was $124.8 \mathrm{mg} / \mathrm{dl}$ (normal range, $150-340 \mathrm{mg} / \mathrm{dl}$ ), the fibrin degradation product (FDP) level was $225.3 \mu \mathrm{g} / \mathrm{ml}$ (normal range, $0-8 \mu \mathrm{g} / \mathrm{ml}$ ) and the d-dimer level was $152.1 \mu \mathrm{g} / \mathrm{ml}$ (normal range, $0-1 \mu \mathrm{g} / \mathrm{ml}$ ). On the second day of admission, DCBM with DIC was suspected and a BM biopsy was performed to obtain a definitive diagnosis. On the third day of admission, CT scans of the whole body and bone scintigraphy revealed systemic bone metastasis and multiple small lung metastases. On the fourth day of admission, the pathological examination of BM demonstrated the existence of carcinoma, and the patient was definitively diagnosed with DCBM from curatively resected rectal cancer (Fig. 1). Soon after the definitive diagnosis of DCBM, systemic chemotherapy with a modified folinic acid, leucovorin (LV), 5-fluorouracil (5-FU), and oxaplatin (OX) (mFOLFOX6) regimen was initiated. The following treatment was repeated every 2 weeks: OX $85 \mathrm{mg} / \mathrm{m}, \mathrm{LV} 200 \mathrm{mg} / \mathrm{m}^{2}, 5$-FU bolus $400 \mathrm{mg} / \mathrm{m}^{2}, 5-\mathrm{FU}$ infusion $2,400 \mathrm{mg} / \mathrm{m}^{2}$ over $46 \mathrm{~h}$. Performance Status was 2, and $80 \%$ of the regular dose was administered. On the fifth day of admission, denosumab was administered as a treatment for bone metastases. For treatment of DIC and improvement of the systemic condition, a repeated transfusion of platelet concentrates was performed and anti-DIC treatment consisted of systemic recombinant human thrombomodulin (rTM) and nafamostat mesilate (NM) administered intravenously.

Following the first cycle of mFOLFOX6, blood test results exhibited a platelet cell count of $11.0 \times 10^{4} / \mu 1$ and thrombocytopenia had improved. The blood test was performed using the inclusion criteria of DIC. PT-INR, fibrinogen and FDP levels, and platelet count had improved to $1.16,333.0 \mathrm{mg} / \mathrm{dl}$,

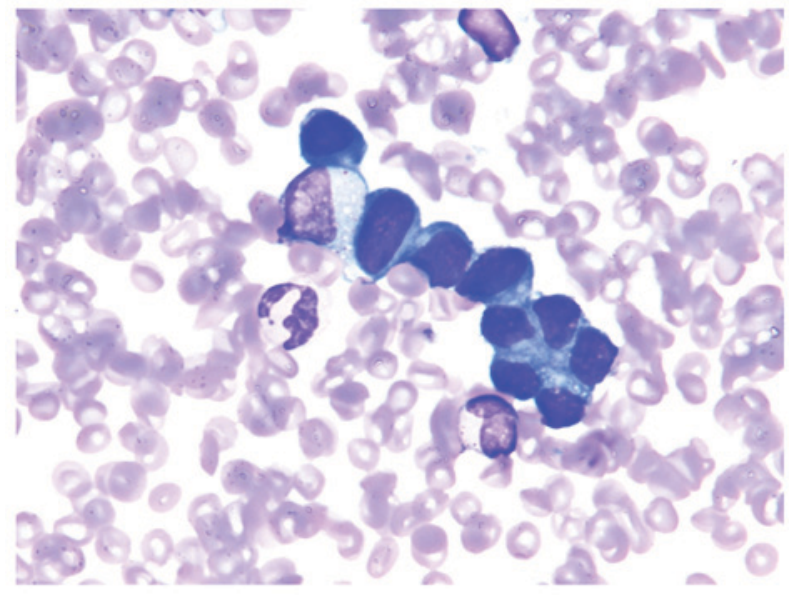

Figure 1. Bone marrow biopsy demonstrating aggregated metastatic cells from the rectal carcinoma (staining, May-Giemsa; magnification, x1,000).

$23.0 \mu \mathrm{g} / \mathrm{ml}$ and $15.1 \times 10^{4} / \mu 1$, respectively. No significant toxicities other than grade 1 diarrhea and anorexia were reported. Following the first cycle of chemotherapy, the tumor marker carcinoembryonic antigen (CEA) dramatically decreased from 346.6 to $21.7 \mathrm{ng} / \mathrm{ml}$. To predict the chemosensitivity of mFOLFOX6, immunohistochemistry (IHC) was performed on the primary lesion for excision repair cross-complementing 1 (ERCC1) and thymidylate synthase (TS). IHC demonstrated no expression of TS and positive expression of ERCC1 (Fig. 2).

After 2 cycles of chemotherapy, the patient was discharged. The same treatment for a total of 12 cycles was continued on an outpatient basis until September 2015, which was 7 months after initiation of chemotherapy. The patient was alive 263 days after the diagnosis of DIC, but succumbed to carcinomatous meningitis in November 2015, which occurred as a result of disease progression.

\section{Discussion}

To the best of our knowledge, the present case is the first to document DCBM with DIC of resected rectal cancer as the initial presentation of recurrence, which was successfully treated with mFOLFOX6 and other anti-DIC therapies, and with a longer prognosis than previous studies as can be observed in Table I. Even when considering including DCBM of colon cancer as the initial site of recurrence, there is only one case that has been reported; however, DCBM was only diagnosed postmortem (10). In the present case, DCBM was diagnosed rapidly and DIC was treated successfully with aggressive therapy, including chemotherapy.

Solid tumors in patients may be the cause of DIC during their clinical course; a frequency of $1.6-6.8 \%$ has been observed among patients with assorted solid tumors $(12,13)$. In addition, a frequency of $0-7.7 \%$ has been reported among patients with colorectal cancer $(12,13)$. The prognosis of patients with solid tumors with DIC is much poorer than those without DIC (13). The exact mechanism resulting in DIC in patients with solid tumors remains unclear (14). However, it is considered that all pathways that contribute to the incidence of DIC are driven by cytokines produced by tumor cells (15). The interactions between malignant cells, monocytes and 

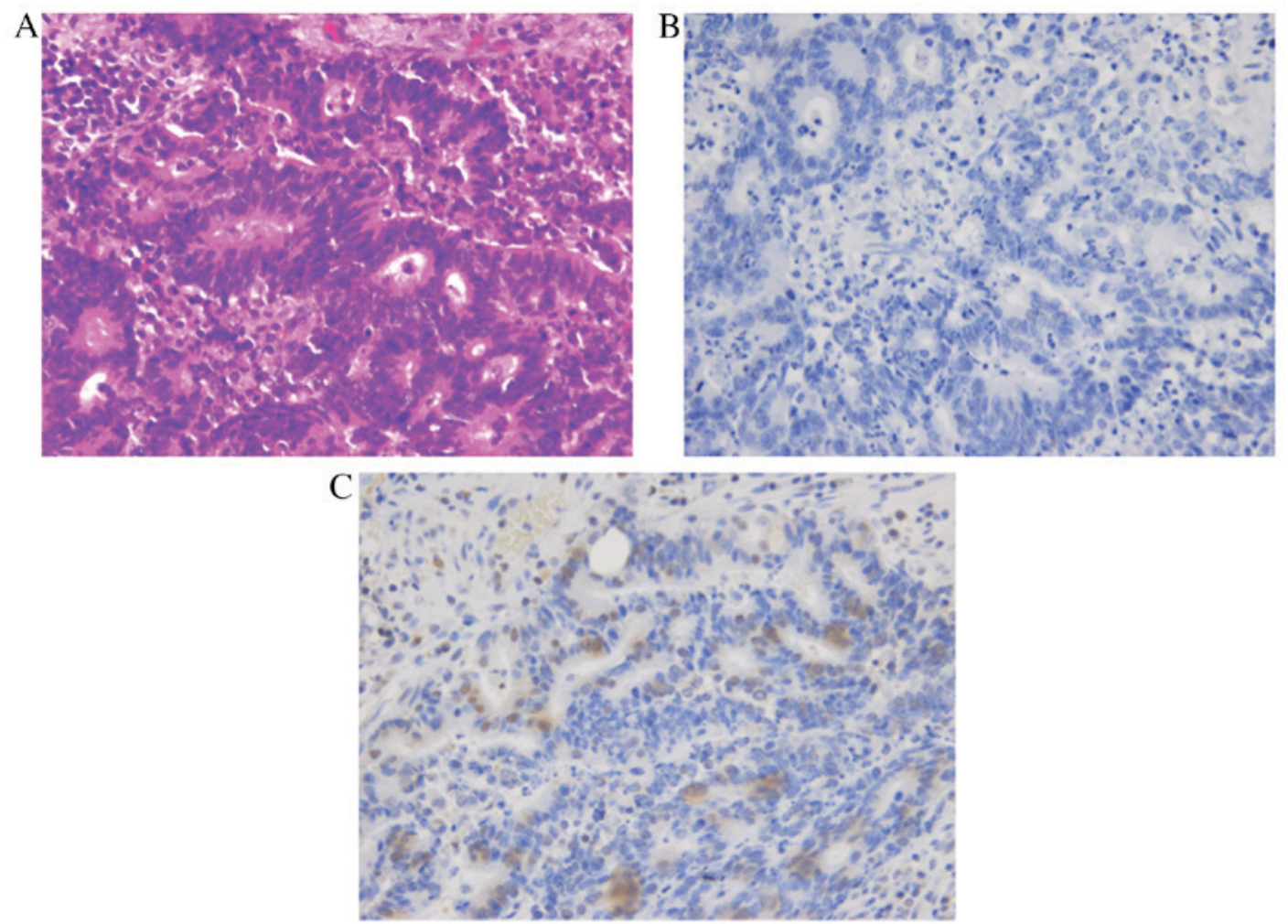

Figure 2. Histological appearance of the first surgical specimen. (A) Hematoxylin and eosin staining demonstrated a moderately differentiated adenocarcinoma of the rectum (magnification, x200). (B) Negative thymidylate synthase immunohistochemical staining (magnification, $\mathrm{x} 200$ ). (C) Positive excision repair cross-complementing 1 immunohistochemical staining (magnification, x200).

macrophages combine to generate tissue factors and secretion cytokines, including tissue necrosis factor, interleukin 1 and interleukin-6 (16). These cytokine-dependent modulators of fibrinolysis and coagulation serve a role in cancer-related DIC.

Cancer-related DIC could occur regardless of the existence of DCBM, and DCBM is not necessarily accompanied by DIC (1). Therefore, DCBM with DIC of colorectal cancer is particularly rare and only seven cases have been reported previously in the literature (Table I). In addition, DCBM has cancer emergency status, and it is sometimes hard to diagnose when a patient is alive and in a condition to withstand chemotherapy. There are only five cases (including the present case) in which chemotherapy was administered (Table I) (5,7-9).

Treatments for DCBM with DIC conform to those for cancer-related DIC. Immediate aggressive supportive treatment in addition to systemic chemotherapy has been the only treatment to improve prognosis thus far (1). When treating DIC, it is important that the underlying disorder is treated with chemotherapy. In fact, if the malignant disease is able to be brought into remission, the DIC may typically disappear simultaneously, as observed in the present case. While anti-DIC treatments without chemotherapy may not improve DIC, all cases in which recovery from DIC was successful were treated with chemotherapy (Table I).

In the current case, mFOLFOX6 dramatically improved DIC. To further evaluate the chemosensitivity of mFOLOFX6, IHC was performed for TS and ERCC1. TS is a key enzyme in DNA and RNA synthesis, and TS expression has been reported to be a useful predictive marker of 5-FU-based chemotherapy $(17,18)$. ERCC1 is implicated in the repair of damaged DNA, and ERCC1 expression has been reported to be a useful predictive marker of platinum-based chemotherapy, including OX (19). In the present case, the expression of these two markers was evaluated in the primary lesion: TS was negative and ERCC1 was positive. Certain previous studies have reported that TS was a better predictive chemosensitivity marker for OX and 5-FU chemotherapy than ERCC1 $(20,21)$. Results of the present study are in agreement with these previous studies in that TS was observed to be a useful predictive chemosensitivity marker of mFOLFOX6.

Supportive anti-DIC treatments consist of the following anticoagulant treatment: rTM, heparin and anticoagulation agents, including NM. Based on the hypothesis that extensive activation of coagulation is characteristic of DIC, a rational treatment approach may be anticoagulant treatment; therefore rTM and NM were administered in the current case. However, the safety and efficacy of these treatments for patients with cancer with DIC has rarely been addressed in clinical studies (22). In the present case, nasal bleeding required repeated coagulation treatment and heparin was not administered to avoid worsening of the nasal bleeding.

Denosumab is a fully human monoclonal antibody against the human receptor activator of nuclear factor- $\kappa \mathrm{B}$ ligand and inhibits osteoclast differentiation (23). Denosumab administration is a potential novel treatment choice for the management of bone metastases (24). Previous studies have demonstrated that it is able to reduce tumor-induced bone destruction and bone resorption (24-26). Although zoledronic acid has also been used in the treatment of bone metastasis (27), several studies have recently reported that denosumab was superior 
to zoledronic acid (24,28-30). Denosumab has been recently included in the treatment in combination with chemotherapy against disseminated carcinomatosis of the BM (9). In the present case, denosumab may also have served a role in adding to the aggressive intensive therapy, resulting in remission of DIC.

In conclusion, in cancer patients with DIC, clinicians should consider DCBM in the differential diagnosis and should perform a BM biopsy without delay to obtain a definitive diagnosis. Once DCBM with DIC is diagnosed, rapid and appropriate treatment management should be performed. An early diagnosis of DIC and the administration of systemic chemotherapy and aggressive supporting anti-DIC therapy may offer certain patients the possibility of recovery from DIC, as described in the current case.

\section{References}

1. Kusumoto H, Haraguchi M, Nozuka Y, Oda Y, Tsuneyoshi M and Iguchi $\mathrm{H}$ : Characteristic features of disseminated carcinomatosis of the bone marrow due to gastric cancer: The pathogenesis of bone destruction. Oncol Rep 16: 735-740, 2006.

2. Anner RM and Drewinko B: Frequency and significance of bone marrow involvement by metastatic solid tumors. Cancer 39 : $1337-1344,1977$

3. Jonsson U and Rundles RW: Tumor metastases in bone marrow. Blood 6: 16-25, 1951.

4. Yoshioka K, Shimizu H, Yokoo S and Andachi H: Disseminated carcinomatosis of bone marrow from submucosal carcinoma in adenoma of the rectum. Intern Med 31: 1056-1059, 1992.

5. Huang WT, Chang KC, Shan YS, Tsao CJ and Lee JC: Successful initial treatment with weekly 24-hour infusion of 5-fluorouracil and leucovorin in a rectal cancer patient with acute disseminated intravascular coagulation. Hepatogastroenterology 52 $1436-1439,2005$.

6. Misawa R, Kobayashi M, Ito M, Kato M, Uchikawa Y and Takagi S: Primary colonic signet ring cell carcinoma presenting carcinocythemia: An autopsy case. Case Rep Gastroenterol 2: 301-307, 2008.

7. van Bunderen CC, de Weger VA and Griffioen-Keijzer A: Disseminated intravascular coagulation as clinical manifestation of colorectal cancer: A case report and review of the literature. Neth J Med 72: 186-189, 2014.

8. Nakashima Y, Takeishi K, Guntani A, Tsujita E, Yoshinaga K, Matsuyama A,Hamatake M, Maeda T, Tsutsui S, Matsuda H, et al: Rectal cancer with disseminated carcinomatosis of the bone marrow: Report of a case. Int Surg 99: 518-522, 2014.

9. Naito M, Yoshida Y, Aisu N, Tanimura S, Hoshino S, Tanaka T, Nimura S, Tamura K and Yamashita Y: A report of disseminated carcinomatosis of the bone marrow originating from transverse colon cancer successfully treated with chemotherapy using XELOX plus bevacizumab. Case Rep Oncol 7: 426-434, 2014.

10. Lim DH, Lee SI and Park KW: Bone marrow metastasis of colon cancer as the first site of recurrence: A case report. Oncol Lett 8: 2672-2674, 2014

11. Kobayashi N, Maekawa T, Takada M, Tanaka H and Gonmori H: Criteria for diagnosis of DIC based on the analysis of clinical and laboratory findings in 345 DIC patients collected by the research committee on DIC in Japan. Bibl Heamatol: 265-275, 1983.

12. Pasquini E, Gianni L, Aitini E, Nicolini M, Fattori PP, Cavazzini G, Desiderio F, Monti F, Forghieri ME and Ravaioli A Acute disseminated intravascular coagulation syndrome in cancer patients. Oncology 52: 505-508, 1995.

13. Sallah S, Wan JY, Nguyen NP, Hanrahan LR and Sigounas G: Disseminated intravascular coagulation in solid tumors: Clinical and pathologic study. Thromb Haemost 86: 828-833, 2001.

14. Levi M and Ten Cate H: Disseminated intravascular coagulation. N Engl J Med 341: 586-592, 1999.

15. Levi M: Disseminated intravascular coagulation in cancer patients. Best Pract Res Clin Haematol 22: 129-136, 2009.
16. Esmon CT: Possible involvement of cytokines in diffuse intravascular coagulation and thrombosis. Baillieres Best Pract Res Clin Haematol 12: 343-359, 1999.

17. Koopman M, Venderbosch S, Nagtegaal ID, van Krieken JH and Punt CJ: A review on the use of molecular markers of cytotoxic therapy for colorectal cancer, what have we learned? Eur J Cancer 45: 1935-1949, 2009.

18. Kumamoto K, Kuwabara K, Tajima Y, Amano K, Hatano S, Ohsawa T, Okada N, Ishibashi K, Haga N and Ishida $\mathrm{H}$ : Thymidylate synthase and thymidine phosphorylase mRNA expression in primary lesions using laser capture microdissection is useful for prediction of the efficacy of FOLFOX treatment in colorectal cancer patients with liver metastasis. Oncol Lett 3: 983-989, 2012.

19. Altaha R, Liang X, Yu JJ and Reed E: Excision repair cross complementing-group 1: Gene expression and platinum resistance. Int J Mol Med 14: 959-970, 2004.

20. Shirota Y, Stoehlmacher J, Brabender J, Xiong YP, Uetake H, Danenberg KD, Groshen S, Tsao-Wei DD, Danenberg PV and Lenz HJ: ERCC1 and thymidylate synthase mRNA levels predict survival for colorectal cancer patients receiving combination oxaliplatin and fluorouracil chemotherapy. J Clin Oncol 19: 4298-4304, 2001.

21. Arienti C, Tesei A, Verdecchia GM, Framarini M, Virzi S, Grassi A, Scarpi E, Turci L, Silvestrini R, Amadori D and Zoli W: Role of conventional chemosensitivity test and tissue biomarker expression in predicting response to treatment of peritoneal carcinomatosis from colon cancer. Clin Colorectal Cancer 12: 122-127, 2013

22. Blake P, Delicata R, Cross N, Sturgeon G and Hargest R: Large bowel obstruction due to colorectal carcinoma can be safely treated by colonic stent insertion-case series from a UK district general hospital. Colorectal Dis 14: 1489-1492, 2012.

23. Lacey DL, Timms E, Tan HL, Kelley ML, Dunstan CR, Burgess T, Elliott R, Colombero A, Elliott G, Scully S, et al: Osteoprotegerin ligand is a cytokine that regulates osteoclast differentiation and activation. Cell 93: 165-176, 1998.

24. Stopeck AT, Lipton A, Body JJ, Steger GG, Tonkin K, de Boer RH, Lichinitser M, Fujiwara Y, Yardley DA, Viniegra M, et al: Denosumab compared with zoledronic acid for the treatment of bone metastases in patients with advanced breast cancer: A randomized, double-blind study. J Clin Oncol: 28: 5132-5139, 2010.

25. Fizazi K, Lipton A, Mariette X, Body JJ, Rahim Y, Gralow JR Gao G, Wu L, Sohn W and Jun S: Randomized phase II trial of denosumab in patients with bone metastases from prostate cancer, breast cancer, or other neoplasms after intravenous bisphosphonates. J Clin Oncol 27: 1564-1571, 2009.

26. Smith MR, Egerdie B, Hernández Toriz N, Feldman R, Tammela TL, Saad F, Heracek J, Szwedowski M, Ke C, Kupic A, et al: Denosumab in men receiving androgen-deprivation therapy for prostate cacner. N Engl J Med 361: 745-755, 2009.

27. Misso G, Porru M, Stoppacciaro A, Castellano M, De Cicco F, Leonetti C, Santini D and Caraglia M: Evaluation of the in vitro and in vivo antiangiogenic effects of denosumab and zoledronic acid. Cancer Biol Ther 13: 1491-1500, 2012.

28. Henry DH, Costa L, Goldwasser F, Hirsh V, Hungria V, Prausova J, Scagliotti GV, Sleeboom H, Spencer A, Vadhan-Raj S, et al: Randomized, double-blind study of denosumab versus zoledronic acid in the treatment of bone metastases in patients with advanced cancer (excluding breast and prostate cancer) or multiple myeloma. J Clin Oncol 29: 1125-1132, 2011

29. Scagliotti GV, Hirsh V, Siena S, Henry DH, Woll PJ, Manegold C, Solal-Celigny P, Rodriguez G, Krzakowski M, Mehta ND, et al: Overall survival improvement in patients with lung cancer and bone metastases treated with denosumab versus zoledronic acid: Subgroup analysis from a randomized phase 3 study. J Thorac Oncol 7: 1823-1829, 2012.

30. Fizazi K, Carducci M, Smith M, Damião R, Brown J, Karsh L, Milecki P, Shore N, Rader M, Wang H, et al: Denosumab versus zoledronic acid for treatment of bone metastases in men with castration-resistant prostate cancer: A randomised, double-blind study. Lancet 377: 813-822, 2011. 